\title{
Fine-scale oceanographic features characterizing successful Adélie penguin foraging in the SW Ross Sea
}

\author{
Grant Ballard $^{1, *}$, Annie E. Schmidt ${ }^{1}$, Viola Toniolo ${ }^{1,2}$, Sam Veloz ${ }^{1}$, \\ Dennis Jongsomjit ${ }^{1}$, Kevin R. Arrigo ${ }^{2}$, David G. Ainley ${ }^{3}$ \\ ${ }^{1}$ Point Blue Conservation Science, Petaluma, CA 94954, USA \\ ${ }^{2}$ Department of Earth System Science, Stanford University, Stanford, CA 94305, USA \\ ${ }^{3}$ H.T. Harvey \& Associates, Los Gatos CA 95305, USA
}

\begin{abstract}
According to central place foraging theory, breeding seabirds should energetically optimize prey acquisition and, therefore, foraging is expected to be located where prey are most available, within limits defined by the energetics of the species. We have shown this previously for Adélie penguins Pygoscelis adeliae, using foraging intensity as a proxy for prey patch quality, but we have yet to assess the habitat characteristics where foraging success is highest. Here, we report an effort using biologging instruments that recorded location and an index of foraging success, allowing us to characterize aspects of more or less successful foraging locations on the basis of sea-surface temperature, chlorophyll concentration, sea ice cover, water column stratification, and bathymetry. We retrieved data from 162 breeding Adélie penguins over 5 austral summers, 2005-2008 and 2012, and used a machine-learning algorithm to model the relationship between the number of undulations $(>1 \mathrm{~m})$ penguins made (i.e. our index of foraging success) and oceanographic conditions at the fine scale $(5 \mathrm{~km})$. We found that most oceanographic features were not predictive of foraging success, although light availability and thermocline strength as measured at the scale of individual penguin foraging dives were both relatively strong predictors. Contrary to previous results obtained at larger scales, we showed that at the fine scale, sea ice concentration is not an important predictor of foraging success, although the associated effect of sea ice cover, i.e. a stratified water column as indicated by thermocline strength, was important. We also confirmed that penguins traveled farther to achieve the same foraging success later in the season despite consistent oceanographic features, indicating that prey become depleted as the breeding season progresses. Our findings suggest that finer spatial and temporal scale data, including from underwater, are necessary to accurately describe the environmental variables that correlate with penguin foraging success, reinforcing the promise of small, animal-borne sensors for evaluating ecosystem processes.
\end{abstract}

KEY WORDS: Foraging behavior $\cdot$ Seabird habitat $\cdot$ Prey depletion $\cdot$ Thermocline $\cdot$ Sea ice $\cdot$ Ross Sea . Adélie penguin $\cdot$ Pygoscelis adeliae

\section{INTRODUCTION}

Habitat use by wildlife reflects the species' requirements and specialization, and the extent to which the available habitat varies. Populations can be threatened or bolstered by changes to habitat, driven by natural environmental variation as well as by anthropogenic causes. Thus, understanding a species' habi-

${ }^{*}$ Corresponding author: gballard@pointblue.org tat requirements and monitoring wildlife populations' responses to habitat change facilitates effective conservation and management (Ballard et al. 2012). This understanding is especially critical in the context of rapid environmental change, acknowledging the potential for trophic cascades and other forms of ecosystem response (Ainley et al. 2015). Quantifying requirements for pelagic marine species is particu-

(C) The authors 2019. Open Access under Creative Commons by Attribution Licence. Use, distribution and reproduction are unrestricted. Authors and original publication must be credited. 
larly challenging because their preferred habitat may be highly dynamic, changing rapidly in space and time. Nonetheless, insights into habitat requirements may be gained by determining correlations between temporally and spatially varying habitat characteristics and indices of habitat suitability, such as foraging success.

The at-sea habitat used by seabirds is determined in large part by the trade-offs between prey availability in these habitats and limits defined by the energetics of the species, but because actual measurements of prey availability are hard to acquire, researchers have commonly used metrics of physical and biological oceanographic processes that are heterogeneous, scale-dependent, and closely tied, at the meso- and finer scale, to prey distribution (summarized in Ballance et al. 2001, Shealer 2002). At small scales, prey can be patchy and may require a concerted effort by predators to locate (Veit 1999, Silverman et al. 2004, Nevitt et al. 2008). Additionally, seabirds are centralplace foragers which, during the breeding season, must return to feed their young between foraging bouts. As such, they are presented with the additional challenge of having to optimize prey acquisition despite having potentially significant travel time and distance constraints (Orians \& Pearson 1979). This challenge is particularly acute for penguins, which (because they are flightless) cannot search large areas and rely on short-distance cues, and to some extent, memory, when locating prey patches (Ford et al. 2015). These additional constraints on the available foraging area may make prey depletion over the course of a breeding season particularly likely for large penguin colonies. What may have been suitable habitat becomes unsuitable as more and more penguins attempt to forage in the same constrained area, causing prey availability to decline. Several previous studies on Adélie penguins Pygoscelis adeliae have found that foraging distance, duration, and energetic effort increased as the season progressed, especially as a function of colony size, with the largest colony undergoing the greatest change. We have previously provided evidence that this reflects competition-induced depletion of prey, especially when other top predators are present (Ainley et al. 2004, 2006, 2015, Ballance et al. 2009, Ford et al. 2015).

In addition to the biological considerations described above, foraging success can be affected by oceanographic features. Most studies that link higher trophic activity to oceanography have focused on large and mesoscale features (e.g. Russell et al. 1999, Hamer et al. 2000, Ribic et al. 2011). Several studies have found positive correlations between seabird density and various physical features, such as seasurface temperature (SST), that define areas of prey aggregation at the mesoscale and above, and sometimes to the fine scale ( $5 \mathrm{~km}$ or less; reviewed by Bost et al. 2009, Ainley et al. 2012). At the mesoscale and larger, aggregations of predators appear to coincide with areas of higher productivity that are often associated with predictable features such as bathymetric gradients and eddies (Yen et al. 2004, 2005, Ainley et al. 2009), while foraging success can be related to such features as a strong thermocline or pycnocline (Shealer 2002, Ropert-Coudert et al. 2009, Pelletier et al. 2012). There are also individual and behavioral constraints that affect where individuals forage and how successful they are. Penguins are visual predators and their ability to access prey at depth is limited by the need for sufficient light to see their prey (Wilson et al. 1993, Ainley \& Ballard 2012). Additionally, there are energetic and physiological constraints that limit how deep a penguin of a particular size may dive (Kooyman 1989).

The cost and logistical difficulties of collecting in situ data in the Southern Ocean limit the scope of atsea studies, especially where persistent sea ice often constrains navigational routes, although the use of autonomous vehicles is starting to change this (Kahl et al. 2010, Oliver et al. 2013, Ainley et al. 2015, Cimino et al. 2016). Advances in bio-logging technologies have led to the development of small, streamlined devices that are attached directly to free-ranging marine animals and can help to gain further insight into their habitat use and foraging success, especially when combined with remotely sensed oceanographic data (see review in Bost et al. 2009). While this technology does not replace real-time ocean sampling of predators and prey (e.g. Ainley et al. 2015, Cimino et al. 2016), it does allow us to quantify an individual predator's behavior at very fine scales and over a broad range in its search for, and exploitation of, prey patches.

Previous work using data collected on at-sea surveys in the Ross Sea showed that, at the large scale and across 9 species, most of the region was used by predators with distinctive niche separation into 3 general habitat types: the continental shelf-break, the shelf, and the marginal ice zone (MIZ) surrounding the Ross Sea post-polynya (Ballard et al. 2012). While several species (including Adélie penguins) showed affinities for the MIZ, these were coarse and did not include measures of foraging success. This previous work also included data from outside of the Adélie penguin breeding season as well as observations of individuals that were not necessarily breed- 
ers during breeding season. Non-breeders are less constrained than breeders because breeding individuals need to return to the nest site to feed chicks, as well as cope with potentially higher intra-specific competition given the large numbers of other penguins that are trying to do the same thing at the same time in the same foraging area.

Here we investigated whether it is possible to determine habitat quality at a finer and more mechanistic scale than previously attempted in the Ross Sea. In accord with studies elsewhere (Kahl et al. 2010, Oliver et al. 2013), we hypothesize that there are persistent habitat features corresponding to variability in Adélie penguin foraging success. To evaluate this hypothesis, we combined 5 years of Adélie penguin tracking and diving data from the southwestern (SW) Ross Sea with a set of remotely-sensed habitat variables to determine the relative roles of small and fine-scale oceanographic habitat features and/or the behavioral constraints in predicting Adélie penguin foraging success.

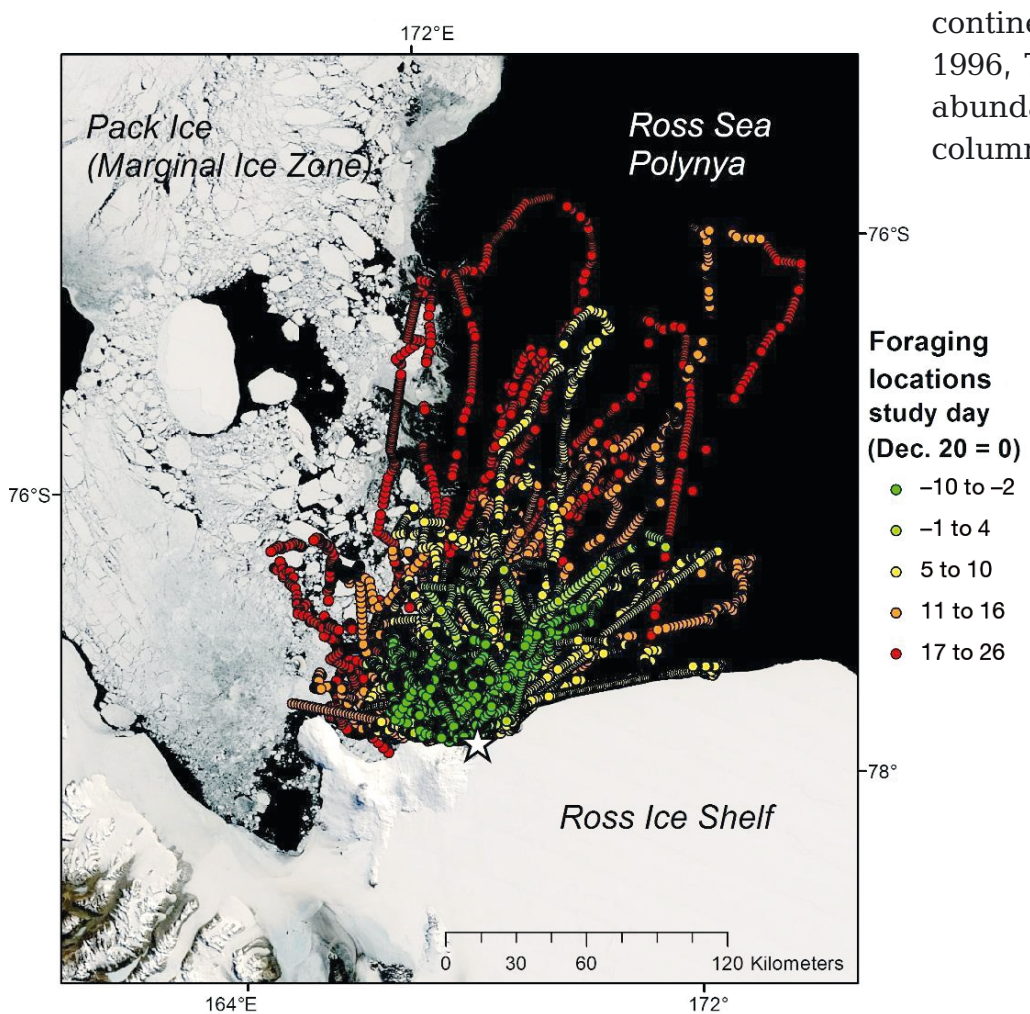

Fig. 1. Study area and foraging locations of 162 Adélie penguins that were feeding chicks at Cape Crozier (white star) in the years 2005-2006 to 2008-2009 and 2012-2013. Base satellite image acquired by the MODerate-resolution Imaging Spectroradiometer (MODIS) on board the Terra satellite on 13 December 2007 (courtesy of Rapid Response imagery from the Land, Atmosphere Near real-time Capability for Earth Observing System operated by the NASA/GSFC/Earth Science Data and Information System with funding provided by NASA/HQ)

\section{MATERIALS AND METHODS}

\subsection{Study area and Ross Sea ecosystem}

Data were collected in the ocean off Cape Crozier $\left(77.8270^{\circ} \mathrm{S}, 169.8120^{\circ} \mathrm{E}\right)$, the largest Adélie penguin colony on Ross Island in the SW Ross Sea, and possibly the world (with as many as 272340 pairs during this study; Lynch \& LaRue 2014, Lyver et al. 2014; Fig. 1).

The diet of Adélie penguins in the SW Ross Sea is composed primarily of Antarctic silverfish Pleuragramma antarcticum and crystal krill Euphausia crystallorophias (Ainley et al. 1998, 2003, 2015). Crystal krill graze on diatoms, while silverfish feed on krill and their own larvae and eggs (Eastman 1985, Hopkins 1987, Pakhomov \& Perissinotto 1997); both play a key role in a complex food web (reviewed by La Mesa et al. 2004, Smith et al. 2007, 2014; see also Ainley et al. 2010, 2015). Both prey species exhibit diel vertical migrations (Ainley et al. 2015). Crystal krill are most abundant in the mid-layers of continental shelf waters (Pakhomov \& Perissinotto 996, Taki et al. 2008) while silverfish are the most undant juvenile and postlarval fish in the water in the region (DeWitt 1970, LaMesa \& Eastman 2012, Pinkerton et al. 2013), common from the surface to about $400 \mathrm{~m}$ depth (Eastman 1993, LaMesa \& Eastman 2012). Silverfish are a major component of the diet of all surface feeding seabirds in the shelf waters of the Ross Sea (Ainley et al. 1984).

The Ross Sea is the most extensive continental shelf ecosystem and most productive stretch of water in the Southern Ocean, contributing $\sim 28 \%$ of Southern Ocean primary production (Arrigo et al. 1998, 2002, 2008). The shelf is deepest near the coast $(\sim 1000 \mathrm{~m})$, sloping upward with increasing distance away, and is deeper than the shelves of other continents. Other than having a westward current along the shelf break (outermost $800 \mathrm{~m}$ isobath), as part of the Ross Gyre (Jacobs et al. 2002), waters of the Ross Sea shelf are largely dominated by mesoscale and small-scale processes controlled by a complex of banks and troughs. Modified circumpolar deep water intrudes into the outer portions of the troughs (Smith et al. 2014). During winter and early spring the Ross Sea is covered almost fully by pack ice, with the exception of several yearround polynyas, and particularly the Ross 
Sea polynya which projects northward from the outer margin of the Ross Ice Shelf (Jacobs \& Comiso 1989, Arrigo et al. 2015; Fig. 1). In all but approximately the eastern third of its area, the Ross Sea becomes ice free by February, although the 'ice-free season' has become rapidly shorter, at least since the beginning of satellite-based monitoring in 1979 (Parkinson 2002, Stammerjohn et al. 2012). During the short austral spring and summer, persistent winds force deep mixing of central waters, while ice melt and solar heating lead to increased stratification within the marginal ice zone (MIZ) of the dominating Ross Sea polynya (Smith \& Nelson 1986). A period of short but extremely high nutrient uptake and phytoplankton growth occurs (Smith et al. 2007, 2014), which is primarily controlled by light (daily surface irradiance, cloud cover), SST, and nutrient availability (Smith et al. 2014). Sea-ice dynamics (e.g. formation, advection, and melt) in this region are largely driven by wind and temperature (Jacobs \& Comiso 1989, Arrigo \& van Dijken 2004), with ice melt contributing strongly to water column stratification (Smith \& Nelson 1986).

Studies that utilize satellite imagery to detect oceanographic patterns have described a speciesspecific pattern of phytoplankton growth in the region (Arrigo et al. 1999, 2000, Arrigo \& van Dijken 2004): the first and largest bloom, which is dominated by Phaeocystis antarctica, appears in early spring (approximately the first week of November) in the unstratified, wind-mixed waters of the Ross Sea polynya, and begins to decline by the end of December (Smith et al. 2014). The second, much smaller bloom, which is dominated by diatoms, forms in late December and appears in the highly stratified waters associated with the MIZ). While diatoms are known to be the primary source of biomass for upper trophic levels, $P$. antarctica appears to be little grazed (Haberman et al. 2002; reviewed in Smith et al. 2007, 2014). Therefore, the highest densities of upper level predators are found in the MIZ of the Ross Sea postpolynya (Karnovsky et al. 2007).

\subsection{SPLASH tags}

In 2005, the 'SPLASH' tag (Wildlife Computers) became available, combining Argos satellite tracking with an archival time-depth recorder (TDR) into a single package suitable for deployment on medium-sized penguins, and allowing for the simultaneous sampling of diving behavior and geographic foraging loca- tions. SPLASH tags have been used previously on Adélie penguins (Lescroël et al. 2010, Ballard et al. 2010a, Ford et al. 2015, Ainley et al. 2015). Our study period included 2 thirds of the chick-rearing period, mid-December to mid-January, for 5 austral summers, 2005-2006, 2006-2007, 2007-2008, 2008-2009, and 2012-2013. Hereafter, we refer to austral summers as study seasons, using the final 2 digits from each year (e.g. 0506 refers to the breeding season that began in October 2005 and ended in February 2006). Adult penguins were randomly selected and captured by hand at their nests. All birds had 1 or 2 chicks at the time they were studied. During the guard stage (1 or both parents present at the nest; 10-31 December) we selected the departing adults immediately following a parental nest shift, and during the crèche stage (chicks group together in the absence of parents; 1-15 January) we selected only adults that were known to be provisioning at least 1 chick. Sex was determined whenever possible by visual and/or behavioral means (Ainley \& Emison 1972)

We equipped a total of 184 adult birds (Table 1) with SPLASH tags as well as small, streamlined cylindrical radio transmitters $(46 \mathrm{~mm}$ long, $14 \mathrm{~mm}$ diameter, 8 g; model A2630, Advanced Telemetry Systems) that helped locate the bird once it was back at the colony. SPLASH tags are outfitted with a flexible, $18 \mathrm{~cm}$ antenna that transmits locations via satellite (the sampling interval depends on when the bird is at the surface) and an archival component that records depth (resolution $\pm 0.5 \mathrm{~m}$, accuracy $\pm 1 \%$ ), light (relative irradiance; unspecified units; see 'Discussion'), and temperature (resolution $\pm 0.05^{\circ} \mathrm{C}$, accuracy $\left.\pm 0.1^{\circ} \mathrm{C}\right)$ at $1 \mathrm{~Hz}$; they weighed $62 \mathrm{~g}(1.6 \%$ of a $4 \mathrm{~kg}$ Adélie penguin), had a cross-sectional area of $3.2 \times 10^{-4} \mathrm{~m}^{2}(1.0-1.6 \%$ of a penguin's cross-sectional area), and were attached on the lower back, which is optimal for swimming penguins (Bannasch et al. 1994). One or 2 consecutive trips were recorded for each equipped individual. All tags were affixed in a

Table 1. Numbers of SPLASH tags deployed and retrieved at Cape Crozier, by study season and sex

\begin{tabular}{|lccccc|}
\hline $\begin{array}{l}\text { Study } \\
\text { season }\end{array}$ & Deployed & Retrieved & Females & Males & $\begin{array}{c}\text { Unknown } \\
\text { sex }\end{array}$ \\
\hline $2005-2006$ & 24 & 21 & 11 & 9 & 1 \\
$2006-2007$ & 40 & 33 & 11 & 14 & 8 \\
$2007-2008$ & 36 & 32 & 12 & 14 & 6 \\
$2008-2009$ & 32 & 29 & 12 & 13 & 5 \\
$2012-2013$ & 52 & 47 & 14 & 24 & 9 \\
Totals & $\mathbf{1 8 4}$ & $\mathbf{1 6 2}$ & $\mathbf{6 0}$ & $\mathbf{6 5}$ & $\mathbf{2 9}$ \\
\hline
\end{tabular}


very consistent manner (using a template; light sensor facing up) to the back feathers with black Tesa tape (Wilson \& Wilson 1989, Ballard et al. 2001). Radio transmitters were not used in season 1213. Similar packages and attachment techniques were found to not affect Adélie penguin foraging trip duration or breeding success, even for penguins that were instrumented for more than 20 d (Ballard et al. 2001), but it is possible that the instrumentation had effects that we were unable to detect. A small number of SPLASH tags malfunctioned or lost battery power, some were lost (the bird returned without a tag), and some birds outfitted with tags did not return to the colony (the birds headed northeast to commence fall migration; as reported in Ballard et al. 2010a). In total, 162 returning individuals that successfully provided data were included in this study.

All satellite transmissions were received and processed within the Argos system (CLS Corporation). Satellite positions were filtered using the 'Argosfilter' package for R (Freitas 2010), which first removes all records with invalid locations (Argos class Z), then all locations that require unrealistic swimming speeds (a sustained average of $>2.3 \mathrm{~m} \mathrm{~s}^{-1}$ ), and finally removes offshoots from main paths with angles smaller than $15^{\circ}$ and $25^{\circ}$ if their distance is $>2500 \mathrm{~m}$ and $>5000 \mathrm{~m}$, respectively (Freitas et al. 2008). Because raw Argos positions are biased by satellite orbital parameters and the penguins' latitudinal positions (Georges et al. 1997), and to be able to assign the diving data to a reasonable approximation of a location, we used a linear interpolation algorithm (Tremblay et al. 2006) to create a temporally uniform distribution of locations every $15 \mathrm{~min}$ along each track (Ainley et al. 2015).

Diving data were processed using the program 'divesum' (v.8.1; G. Ballard, unpubl. software; cf. Lescroël et al. 2010, Ainley et al. 2015). This program corrected the record baseline and computed several individual dive parameters, including maximum dive depth, number of undulations (number of changes in underwater swimming direction, with vertical speed going through 0 , from ascent to descent $>1 \mathrm{~m}$, and within the bottom $40 \%$ of the dive in terms of depth), light level at $5 \mathrm{~m}$ depth, and light level at the maximum dive depth. Light level was recorded by the SPLASH tags in a dimensionless value representing relative irradiance. An index of thermocline strength was calculated on the basis of the maximum temperature difference between the mean temperature recorded by SPLASH tags between 4.5 and $5.5 \mathrm{~m}$ and any other temperature recorded at greater depths during any given dive. Prior work in the Ross Sea rarely found vertical profiles of density (or temperature or salinity) that exhibit a gradual change with depth, especially in the spring and summer, so a strong temperature difference recorded by the splash tags likely indicates the presence of a strong thermocline (Arrigo et al. 1998, 2000, Gerringa et al. 2015). We excluded all shallow dives $(<10 \mathrm{~m})$ from the analysis because foraging and traveling dives are difficult to distinguish at shallower depths (Takahashi et al. 2004) and to ensure that enough of the water column was sampled to calculate the index of thermocline strength.

Because of the differences in temporal resolution between the dive (1 s) and satellite (15 min, after interpolation) data, we used temporal proximity to assign a geographic location to each dive. In order to exclude highly interpolated data, we excluded all dives that were interpolated to $>30$ min from a known dive location. We chose $30 \mathrm{~min}$ because at $2.3 \mathrm{~m} \mathrm{~s}^{-1}$, a penguin can travel up to $8.3 \mathrm{~km}$ in $1 \mathrm{~h}$, which is comparable with the spatial resolution of the remotely sensed data used in this model, summarized below (4 to $25 \mathrm{~km}$; Table 2).

Previous studies on Adélie, chinstrap ( $P$. antarcticus), and Magellanic (Spheniscus magellanicus) penguin diving behavior have demonstrated that the number of undulations in penguin movement at the bottom of a dive has a positive linear relationship to the number of prey captured (RopertCoudert et al. 2001, Simeone \& Wilson 2003, Takahashi et al. 2004, Bost et al. 2007). Ropert-Coudert et al. (2001) also found that food was ingested while swimming in an upward direction (backlighting-ofprey effect) during an undulation (see also Watanabe et al. 2014). Ford et al. (2015) and Cimino et al. (2016) used foraging effort (frequency of foraging dives, and foraging bouts) to identify location of suitable prey patches, but Watanabe \& Takahashi (2013) note that the success of penguins during a foraging trip was dependent on a few very successful dives, rather than the number of dives. Therefore, we used the number of undulations per dive as an index of foraging success.

\subsection{Remote sensing}

\subsubsection{Sea ice cover}

For the months of January and December, December 2005-January 2009, we obtained sea ice concentration data from the Advanced Microwave Scanning Radiometer (AMSR-E) aboard the NASA EOS Aqua 
Table 2. Environmental variables used to model Adélie penguin undulations per dive. NA: not applicable

\begin{tabular}{|c|c|c|c|}
\hline & Description & Mean (range) & $\begin{array}{l}\text { Spatial resolution } \\
\text { (grid size) }\end{array}$ \\
\hline \multicolumn{4}{|c|}{ Non-SPLASH variables } \\
\hline SST & Sea-surface temperature $\left({ }^{\circ} \mathrm{C}\right)$ & $-0.66(-1.99$ to 1.13$)$ & $4 \mathrm{~km}$ \\
\hline Chl a & Chlorophyll a concentration $\left(\mathrm{mg} \mathrm{m}^{-3}\right)$ & $2.06(0.22$ to 32.79$)$ & $4 \mathrm{~km}$ \\
\hline Ice & Sea ice concentration $(\%)$ & $10.13(0$ to 99$)$ & 6.25 to $12 \mathrm{~km}$ \\
\hline Depth & Bathymetric depth (m) & $-728.78(-969.21$ to -69.66$)$ & $100 \mathrm{~m}$ \\
\hline Slope & Slope of bathymetric surface (\%) & $2.08(0$ to 24.3$)$ & $100 \mathrm{~m}$ \\
\hline Colony distance & Distance to colony from dive location (m) & 50510 (400 to 249500 ) & $100 \mathrm{~m}$ \\
\hline \multicolumn{4}{|l|}{ SPLASH variables } \\
\hline Thermocline index & \multicolumn{3}{|l|}{$\begin{array}{l}\text { between the mean temperature }\left({ }^{\circ} \mathrm{C}\right) \text { recorded } \\
\text { by SPLASH tags between } 4.5 \text { and } 5.5 \mathrm{~m} \text { and any } \\
\text { other temperature recorded at greater depths } \\
\text { during any given dive }\end{array}$} \\
\hline Max depth & Maximum depth $(\mathrm{m})$ recorded on each dive & $42.54(10$ to 134$)$ & NA \\
\hline Light at $5 \mathrm{~m}$ & $\begin{array}{l}\text { Light level recorded by SPLASH tags at } 5 \mathrm{~m} \\
\text { (relative irradiance) }\end{array}$ & 171.1 (111 to 195$)$ & NA \\
\hline Light at max & $\begin{array}{l}\text { Light level recorded a maximum dive depth } \\
\text { (relative irradiance) }\end{array}$ & $120(57$ to 187$)$ & NA \\
\hline \multicolumn{4}{|l|}{ Temporal variables } \\
\hline Study day & $\begin{array}{l}\text { Day of year, calculated as number of days } \\
\text { before or after } 20 \text { December each year }\end{array}$ & 7.87 (-10 to 26$)$ & NA \\
\hline Study season & $\begin{array}{l}\text { Study season (austral summer): } 7=0506 \\
8=0607 ; 9=0708 ; 10=0809,14=1213\end{array}$ & NA & NA \\
\hline
\end{tabular}

satellite (Cavalieri et al. 2013). The AMSR-E grid covered the entirety of the Antarctic region daily and had a spatial resolution of $12.5 \mathrm{~km}$. We downloaded the HDF (hierarchical data format) images from the NASA National Snow and Ice Data Center (http:// nsidc.org/data/amsre/order_data.html) in November 2012. We converted the HDF grids to geoTIFFs using FWTools 2.4.7 (Warmerdam 2013).

For the study period of December 2012-January 2013, we obtained sea ice concentration data from the Advanced Microwave Scanning Radiometer (AMSR-2) onboard the Japanese Aerospace Exploration Agency's (JAXA) Global Change Observation Mission (GCOM) satellite (JAXA 2013). The change in data sources was due to the AMSR-E sensor ceasing operation in November 2011. The AMSR-2 grids covered the entirety of the Antarctic region daily with a spatial resolution of $6.25 \mathrm{~km}$. Grids were downloaded as geoTIFFs using JAXA's GCOM portal (https://gportal.jaxa.jp/gpr/?lang=en) in February 2013.

Data from both sensors were converted to a percent sea ice concentration value (i.e. percent ice cover per grid cell). We then created 8-d averages to match the temporal resolution of the other satellite data used in this study (see below). This processing was done using R version 3.3.3 (R Development Core
Team 2017) and the 'raster' package (v. 2.5-8, Hijmans 2016).

2.3.2. Chlorophyll and sea-surface temperature (SST)

Chlorophyll a (chl a) and SST were obtained from 8day level-3 (4 km resolution) data from the Moderate Resolution Imaging Spectroradiometer (MODIS) instrument aboard the NASA EOS Aqua satellite (NASA Goddard Space Flight Center 2013) downloaded from https://oceandata.sci.gsfc.nasa.gov/MODIS-Aqua/. $\mathrm{Chl} a$ and SST data were converted from HDF to GeoTIFF rasters using the 'GDAL' library within FWTools v 2.4.7 (http://fwtools.maptools.org/).

\subsubsection{Bathymetric depth and slope}

We used ArcMap 9.3 (ESRI 2008) to interpolate a $100 \mathrm{~m}$ bathymetric grid for the SW Ross Sea from $50 \mathrm{~m}$ contour lines provided by F. Davey (Davey 2004), and then computed the percent slope using the ArcGIS Spatial Analyst extension (ESRI 2008).

All habitat grid values were attributed to the interpolated point-based dive locations by using the extract function from the 'raster' package in $\mathrm{R}$. 


\subsection{Modeling foraging success}

We developed an environmental model that related the number of undulations per dive to a set of environmental covariates using boosted regression trees (BRT). BRTs are particularly suited to modeling non-linear relationships and complex ecological interactions (Elith et al. 2008) and have been shown to outperform traditional techniques when modeling some types of ecological data (Elith et al. 2006). They are able to accommodate any type of variable, handle missing data, and successfully identify important predictor variables. BRTs are a form of regression but instead of a single model, BRTs combine multiple models, resulting in improved predictive ability. BRT uses 2 algorithms, regression trees and boosting. A regression tree is fitted by partitioning the predictor space into rectangles, identifying sectors where the response is most uniform, and fitting the mean response for observations in each region (De'ath \& Fabricius 2000, Elith et al. 2008, Hastie et al. 2009). Regression trees have some drawbacks in that they do not model smooth functions well and are sensitive to changes in training data (Elith et al. 2008). Boosting improves model accuracy by finding and averaging many rough prediction rules rather than the single most accurate prediction rule (Schapire 2003). This is accomplished as a stagewise process, where successive trees are fitted to the residuals of the set already selected. By shrinking the contributions of each tree and averaging across the final selected set, a more robust model that can fit curvilinear functions is constructed (Buston and Elith 2011, Elith et al. 2008).

Using a random subsample of the data, we ran exploratory models using a range of learning rates $(0.05,0.01,0.005)$ and tree complexities (1 through 5, to allow up to 5-way interactions) with a maximum of 50000 trees, and the predictive deviance was recorded. We selected optimal learning rate and tree complexity values based on models that minimized predictive deviance, and in case of ties, prioritized models with larger learning rates, smaller tree complexities and fewer trees to reduce overfitting (Elith et al. 2008). We fitted a BRT model with 9500 trees (learning rate $=0.05$; tree complexity $=5$ ) and a Poisson distribution. All statistics were performed using the 'dismo' package (version 1.1-4, Hijmans et al. 2017) for R 3.3.3 (R Development Core Team 2017) with additional scripts from Elith et al. (2008), and using the number of undulations per dive as the response variable. We ran 2 sets of models; the first set (hereafter 'environmental model') included all the remotely sensed habitat variables outlined above, as well as season, distance to colony from the interpolated foraging location, and study day (number of days before or after 20 December, the date by which most breeding Adélie penguins have chicks at Cape Crozier). The second set of models included all the same environmental variables plus variables calculated from data recorded directly by the SPLASH tags on each dive: the light level at $5 \mathrm{~m}$ depth, light level at the maximum dive depth, maximum dive depth, and the index of thermocline strength.

For each set of variables, we ran a 5-fold cross-validation by first pooling 4 of the 5 years of data and using these to predict to the fifth year, repeating this for each year of our study. To control for the effect of individuals, we ran an additional 5-fold cross-validation by dividing the 162 individuals into 5 random groups (3 groups with 32 individuals, 2 groups with 33 individuals), pooling 4 of the groups and using these to predict to the 5th group, repeating for each group.

No p-values are calculated for variables in BRTs but the relative influence of individual predictors can be estimated based on the number of times a variable is selected for tree splitting, weighted by the squared improvement to the model as a result of each split, and averaged over all trees (Friedman \& Meulman 2003, Elith et al. 2008). The relative influence of each variable is scaled so that the sum adds to 100 , with higher numbers indicating stronger influence on the response.

Interactions were tested using the 'gbm.interactions' function, which tests whether 2-way interactions have been detected and modelled, and reports their relative strength. The interaction size is assessed by calculating a prediction on the linear scale for each predictor pair, setting all other predictors at their means, fitting a linear model that relates predictions to the predictor pair, and calculating the mean value of the residuals. The magnitude of the residuals increases with the strength of any interaction (Elith et al. 2008, Hijmans et al. 2017). The 10 most important interactions were identified.

\section{RESULTS}

Overall, the environmental model had poor predictive accuracy across years and groups of individuals in the study (mean $[ \pm$ SE] Pearson correlation coefficient between observed and predicted undulations across years was $r=0.04 \pm 0.03$ and $r=0.10 \pm 0.02$ across groups and individuals, respectively; Table 3 ). 
Table 3. Summary of cross-validation predictive model results. In the models in the left column, 4 years of data were used to calibrate models of the number of undulations per dive; data from a fifth year were withheld and used to test model predictions. In the models on the right column, groups were formed based on individuals (32-33 ind. group ${ }^{-1}$ ). Values represent the Pearson correlation between observed and predicted undulations for the withheld year or group

\begin{tabular}{|c|c|c|c|c|c|}
\hline $\begin{array}{l}\text { Withheld } \\
\text { year }\end{array}$ & $\begin{array}{c}\text { With } \\
\text { SPLASH } \\
\text { variables }\end{array}$ & $\begin{array}{c}\text { Without } \\
\text { SPLASH } \\
\text { variables }\end{array}$ & $\begin{array}{l}\text { Withheld } \\
\text { group }\end{array}$ & $\begin{array}{l}\text { With } \\
\text { SPLASH } \\
\text { variables }\end{array}$ & $\begin{array}{c}\text { Without } \\
\text { SPLASH } \\
\text { variables }\end{array}$ \\
\hline 2005-2006 & 0.57 & -0.04 & 1 & 0.57 & 0.06 \\
\hline $2006-2007$ & 0.52 & 0.001 & 2 & 0.62 & 0.17 \\
\hline $2007-2008$ & 0.65 & 0.08 & 3 & 0.57 & 0.07 \\
\hline 2008-2009 & 0.63 & 0.09 & 4 & 0.60 & 0.12 \\
\hline $2012-2013$ & 0.53 & 0.05 & 5 & 0.59 & 0.08 \\
\hline Mean $( \pm S E)$ & $0.58(0.03)$ & $0.04(0.03)$ & Mean $( \pm S E)$ & $0.59(0.01)$ & $0.10(0.02)$ \\
\hline
\end{tabular}

Visualizing the interaction (Fig. 3A) demonstrated a consistent peak in undulations at around 100 relative irradiance units regardless of $\max$ dive depth (Fig. 3A). Light at max depth was also estimated to be much more important than max depth (44.9\% compared to $5.6 \%$ ). The main effect of max depth suggested that undulations were maximized at dives whose maximum depth was $\sim 40 \mathrm{~m}$ when accounting for the average effect of light (Fig. 2).

We found a positive effect of thermocline strength on undulations between $0^{\circ}$ and $1^{\circ} \mathrm{C}$ and then relatively consistent undulations when thermo-

However, the predictive ability of the model increased substantially when variables measured by the SPLASH tags were included $(r=0.58 \pm 0.03$ across years and $r=0.59 \pm 0.01$ across groups and individuals).

When SPLASH tag variables were included in the model, they made up 4 of the top 5 most important variables (measured by \% of relative importance) for predicting undulations. The light level at maximum dive depth was the most influential variable, with a relative importance of $44.9 \%$ (Table 4 ). Thermocline strength was the second most important variable with a relative importance of $7.63 \%$, followed by colony distance $(6.78 \%)$, light at $5 \mathrm{~m}(6.76 \%)$, and max dive depth $(5.62 \%)$. With all SPLASH tag variables in the model, SST, slope, study day, sea ice, and study season were all estimated to have a relative importance of $<5 \%$. The shape of the effect of each explanatory variable (after accounting for the average effect of all other predictors) on undulation is shown in Fig. 2. These plots serve as a basis for interpretation and are not meant to be perfect representations of reality, especially if the model contains strong interactions (Elith et al. 2008).

The effect of light at max depth indicated that the number of undulations was maximal at $\sim 100$ relative irradiance units ( 0.008 lux; see Ainley \& Ballard 2012 for conversions), substantially darker than what humans perceive as dark (Bond \& Henderson 1963). The peaked shape of the relationship suggests that there is an optimum light level for high undulations: too much light or too little light and undulations decline. Light at max depth is negatively correlated with max depth $(\mathrm{r}=-0.86, \mathrm{p}<0.001)$ but there was a relatively strong interaction between these 2 variables (the strongest interaction detected; Table 5). cline strength was $>1^{\circ} \mathrm{C}$. This indicates that foraging success was lowest when the water column was well mixed and there was no difference in temperature between the surface layer and deeper waters.

Undulations tended to increase with distance from the colony and generally declined with study day (although study day was relatively unimportant in the overall model). However, there was only a weak interaction between colony distance and study day (Table 5), suggesting that the relationship between

Table 4. Summary of the relative influence of boosted regression tree (BRT) model predictor variables. See Table 2 for explanation of variables

\begin{tabular}{|lc|}
\hline Variable & Relative influence (\%) \\
\hline With SPLASH variables & \\
Light at max & 44.89 \\
Thermocline index & 7.63 \\
Colony distance & 6.78 \\
Light at 5 m & 6.76 \\
Max depth & 5.62 \\
Bathymetry & 5.43 \\
Chlorophyll a & 5.03 \\
SST & 4.91 \\
Slope & 4.50 \\
Study day & 3.56 \\
Sea ice & 2.81 \\
Study season (austral summer) & 2.8 \\
Without SPLASH variables & \\
Colony distance & 21.65 \\
Bathymetry & 15.60 \\
Slope & 13.83 \\
Chlorophyll a & 13.08 \\
SST & 12.50 \\
Study day & 10.49 \\
Sea ice & 7.12 \\
Study season (austral summer) & 5.72 \\
\hline
\end{tabular}



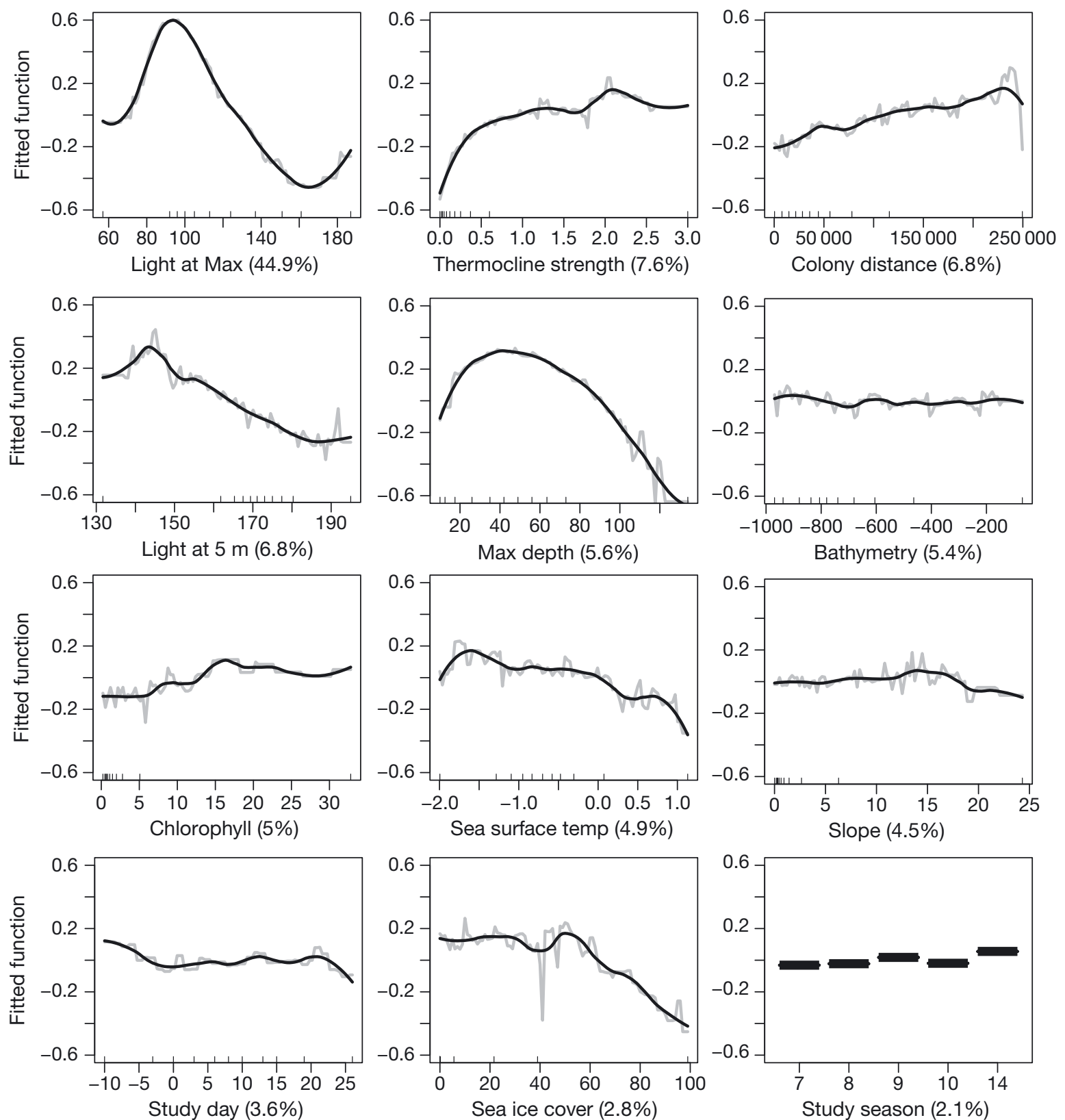

Fig. 2. Results of the boosted regression tree model with SPLASH tag and environmental variables included. The black line is a smoothed version of the fitted function (in grey) which represents undulations per dive of Adélie penguins. Proportional sample sizes are represented by the tick marks on the top of the $x$-axis

undulations and distance did not change much within the season, and that penguins that went farther always had higher success regardless of whether it was early or late in the season. However, distance to colony was positively correlated with study day $(r=0.47$, $\mathrm{p}<<0.001)$, an indication that penguins were having to travel farther to achieve the same foraging success later in the season (Fig. 1). There was a relatively strong interaction between study day and season (Table 5), indicating that the extent to which foraging success declined over the course of the season depended on the year.

Undulations also generally declined with surface brightness (light level at $5 \mathrm{~m}$ depth; Fig. 2). Surface brightness may be affected by several factors including time of day, clouds, ice cover, and chl a concentration. With higher sea ice concentration, the effect of surface brightness on undulations declined as indicated by the relatively strong interaction between ice cover and surface brightness (Table 5). The relation- 
Table 5. Two-way interactions for the BRT model including SPLASH tag measured variables. See Table 2 for explanation of variables. Values indicate relative importance and the top 10 interactions are in bold

\begin{tabular}{|lcccccccccccc}
\hline Variables & $\begin{array}{c}\text { Light } \\
\text { at max }\end{array}$ & $\begin{array}{c}\text { Light } \\
\text { at 5 m }\end{array}$ & $\begin{array}{c}\text { Study } \\
\text { season }\end{array}$ & $\begin{array}{c}\text { Thermo- } \\
\text { cline }\end{array}$ & $\begin{array}{c}\text { Max } \\
\text { depth }\end{array}$ & Chl a & SST & $\begin{array}{c}\text { Bathy- } \\
\text { metry }\end{array}$ & $\begin{array}{c}\text { Slope } \\
\text { Colony } \\
\text { dist. }\end{array}$ & $\begin{array}{c}\text { Sea } \\
\text { ice }\end{array}$ & $\begin{array}{c}\text { Study } \\
\text { day }\end{array}$ \\
\hline Light at max & 0 & 4.21 & 3.19 & $\mathbf{6 . 3 9}$ & $\mathbf{1 5 . 5 7}$ & 1.88 & $\mathbf{5 . 0 9}$ & 2.74 & 2.29 & 2.45 & 2.31 & 3.89 \\
Light at 5m & 0 & 0 & 1.93 & $\mathbf{6 . 1 7}$ & $\mathbf{6 . 4 5}$ & $\mathbf{6 . 5 9}$ & 3.47 & 3.73 & 4.38 & 4.62 & $\mathbf{8 . 2 2}$ & 0.64 \\
Study season & 0 & 0 & 0 & 0.21 & 1.01 & 0.06 & 0.21 & 1.16 & 0.28 & 1.00 & 0.96 & $\mathbf{8 . 9 7}$ \\
Thermocline & 0 & 0 & 0 & 0 & 4.91 & 0.59 & 2.89 & 0.93 & 1.24 & 1.24 & 0.65 & 1.40 \\
Max depth & 0 & 0 & 0 & 0 & 0 & 2.17 & 1.65 & $\mathbf{5 . 4 3}$ & 2.72 & $\mathbf{6 . 3}$ & 1.76 & 2.12 \\
Chl a & 0 & 0 & 0 & 0 & 0 & 0 & 0.5 & 1.41 & 0.4 & 4.93 & 1.09 & 1.53 \\
SST & 0 & 0 & 0 & 0 & 0 & 0 & 0 & 1.87 & 1.99 & 2.31 & 1.41 & 2.59 \\
Bathymetry & 0 & 0 & 0 & 0 & 0 & 0 & 0 & 0 & 2.27 & 5.08 & 2.17 & 2.42 \\
Slope & 0 & 0 & 0 & 0 & 0 & 0 & 0 & 0 & 0 & 1.13 & 0.6 & 0.72 \\
Colony dist. & 0 & 0 & 0 & 0 & 0 & 0 & 0 & 0 & 0 & 0 & 1.38 & 1.43 \\
Sea ice & 0 & 0 & 0 & 0 & 0 & 0 & 0 & 0 & 0 & 0 & 0 & 0.34 \\
Study day & 0 & 0 & 0 & 0 & 0 & 0 & 0 & 0 & 0 & 0 & 0 & 0 \\
\hline
\end{tabular}
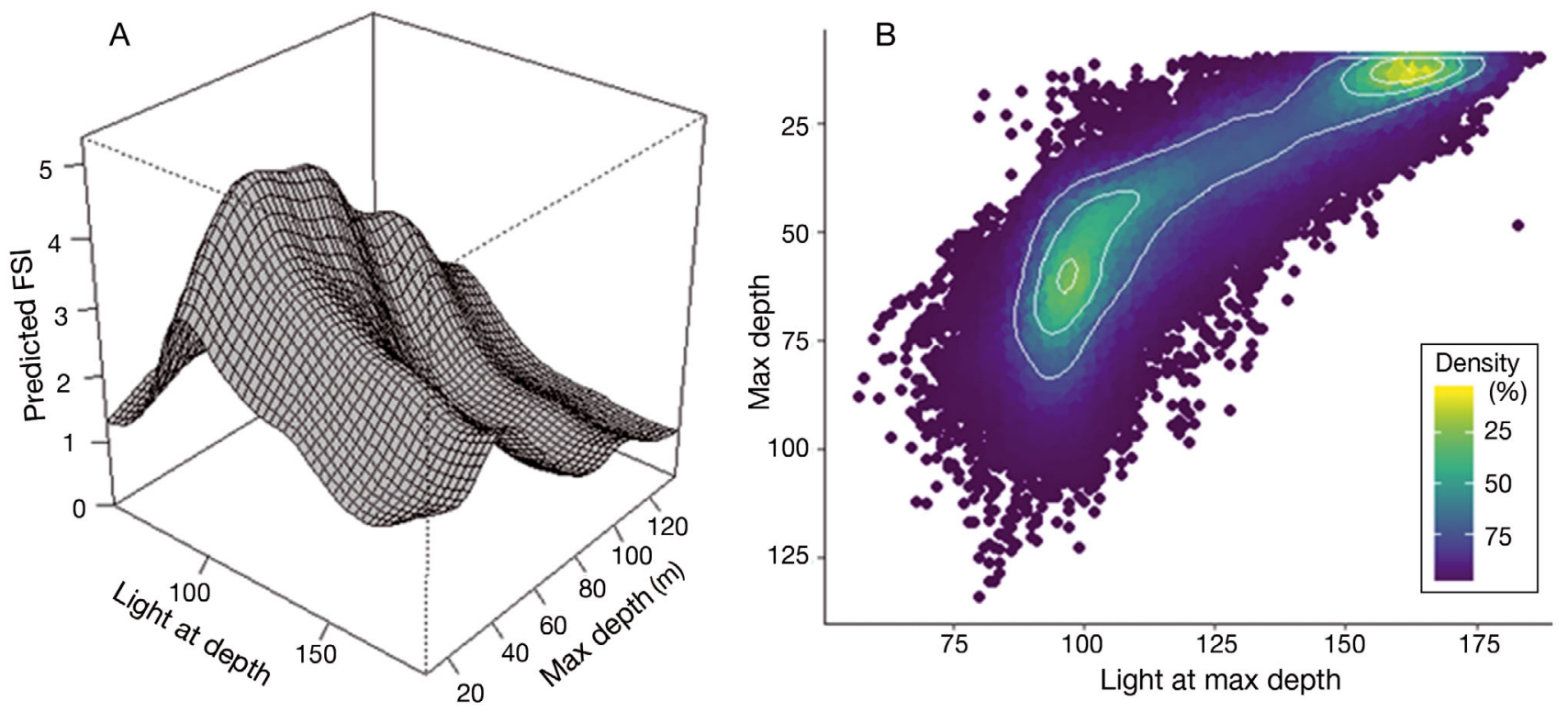

Fig. 3. (A) Strongest interaction from the boosted regression tree model predicting penguin undulations (FSI) with SPLASH tag and environmental variables included: effect of maximum dive depth and light at maximum dive depth; (B) combined distribution of light (relative irradiance; see Section 2.2) measured at the maximum depth of the dive) and max dive depth (note: zero depth/surface is at the top of the plot). Contours delineate bins containing 25,50 and $75 \%$ of the data

ship between undulations and bathymetry was noisy and showed no obvious trend but exhibited the highest undulations in places where water was deeper than $800 \mathrm{~m}$ (Fig. 2). We found that undulations generally increased with chl a up to $15-20 \mathrm{mg} \mathrm{m}^{-3}$ then declined slightly (Fig. 2).

SST, slope, study day, sea ice cover, and study season (austral summer) were all $<5 \%$ in relative importance (Table 4). Undulations generally declined with increasing SST, peaked at slopes between 10 and $15 \%$, declined with study day (mentioned previously), and declined when sea ice cover was $>50 \%$.
Differences in overall undulations between seasons were very slight, with the 0506 study season being the lowest and the 1213 season the highest (study seasons 7 and 14 in Fig. 2, respectively).

\section{DISCUSSION}

Using only relatively static and remotely sensed variables, we were unable to reliably predict variability in the number of undulations per dive, an index of penguin foraging success. However, with 
the addition of very fine-scale environmental and behavioral variables measured on individual dives, we were able to predict penguin foraging success from one year to the next and across groups of individuals. We also confirmed that penguins at this large colony find food patches farther away as the season progresses, presumably due to the effects of prey depletion at patches close to the colony (Fig. 1; Ainley et al. 2015, Ford et al. 2015).

Light level at max dive depth was by far the most important variable determining penguin undulations. Because penguins are visual predators, presumably the amount of light affects their ability to see and catch their prey. The peaked relationship noted here suggests that an optimum light level exists for foraging penguins: too much light, and the prey see the penguins coming and escape, too little light and the penguins cannot see their prey. Prey may concentrate in areas of low light to avoid predation, or they may be rapidly depleted in areas with more light. The interaction between light and max depth suggests that maximum foraging success occurs at a consistent light level. For example, Fig. 3A indicates that undulations are maximized at 100 light units and $40 \mathrm{~m}$ max depth. If a penguin dives greater than $40 \mathrm{~m}$, the number of undulations declines and the curve flattens, but the maximum number of undulations for any max depth is always around 100 light units. This result suggests that penguins may dive to whatever depth necessary to achieve the preferred light level. This interpretation is supported by the 2D distribution of light level and max depth data (Fig. 3B), where $50 \%$ of all dives fall in one of 2 bins, shallow (10-20 m) bright dives with few undulations (low foraging success) or dives centering on 100 light units, but varying in depth from approximately 40-75 m). The importance of light for foraging success was examined previously by Ainley \& Ballard (2012) who noted a slight negative effect of light on foraging success, with the highest success occurring at the lowest light levels. However, the possibility of a curvilinear, or nonlinear relationship between light and foraging success was not explored in that study.

The index of thermocline strength, a measure of water column stratification, was the second most important variable to characterize penguin undulations, suggesting that Adélie penguins locate food most successfully in areas where the upper mixed layer depth is shallow and the water column is more highly stratified, such as the MIZ of the Ross Sea polynya (Smith \& Nelson 1986). These stratified waters occur more commonly late in the summer and are more likely to be dominated by diatoms (Beans et al. 2008, Kropuenske et al. 2009, Arrigo et al. 2010, Mills et al. 2010), which are more readily grazed by krill than P. antarctica (Tagliabue \& Arrigo 2003).

Distance from colony, SST, light at $5 \mathrm{~m}$, bathymetry, chl a concentration and SST had relative model influence scores that were $\leq 5 \%$, suggesting that they played minor roles in penguin foraging success. Given that bathymetry controls the circulation of the sub-mesoscale eddies that populate waters of the Ross Sea shelf (Smith et al. 2014), these variables may well indicate retentive capabilities of these eddies, concentrating phytoplankton (increased chl a) and therefore its grazers. However, together these variables constitute just a proxy for increased prey availability, especially as there is no direct connection between penguin prey and chl $a$ in the Ross Sea (Dugger et al. 2014, Ainley et al. 2015). Prey and phytoplankton concentration are uncoupled in what appears to be a wasp-waist food web structure (Hunt \& McKinnel 2006, Ainley et al. 2015). While certainly the high overall productivity of the Ross Sea explains the high abundance of mesopredators (Smith et al. 2014), interannual, seasonal, and fine-scale spatial variation in phytoplankton concentration has no bearing on penguin breeding success nor changes in diet composition as a function of foraging depth (Dugger et al. 2014, Ainley et al. 2015). This may be in part because penguins, with the help of whales, can deplete their krill and fish prey in surface waters, resulting in an apparent decoupling of phytoplankton abundance and mid-trophic level prey (Ainley et al. 2006, 2015). There is insufficient data on whale spatial distribution and abundance to include as a variable in the model, but if whales are depleting prey in the area, this could contribute to the apparently poor match between penguin foraging success and environmental variables. Bathymetry may also interact with penguin foraging success in a dynamic way that would not have been detected by this analysis. For example, there is evidence supporting the idea that bathymetry and tidal regimes can interact to influence penguin foraging locations (Oliver et al. 2013).

Previous studies show that the effect of sea ice concentration over the entire foraging area on foraging trip duration and food being delivered to chicks is optimized at around $15 \%$ and $12 \%$, respectively (Ballard et al. 2010b, Lescroël et al. 2014), with both high (>20\%) and low (<10\%) sea ice concentration having a negative effect on Adélie penguin foraging and survival for different reasons (Dugger et al. 2010, 2014). Our model, however, shows that at the fine scale $(5 \mathrm{~km})$, sea ice concentration is not an important 
factor determining foraging success, although the residual effects of sea ice cover, i.e. a stratified water column, are important factors.

Our environmental model did a poor job predicting penguin foraging success perhaps in part due to at least 2 shortcomings: (1) habitat variables were limited geographically and in scope to those that are easily quantified via satellite and that have good spatial coverage within our area of interest; and (2) we were unable to include prey distribution data, which is an obvious link between habitat variables and mid-level predators such as penguins in any foraging model. The remotely sensed data included here were available at relatively 'small' scale, nonetheless the factors affecting penguin foraging success either operate at an even finer spatial scale or are dominated by behavioral constraints and decisions rather than habitat constraints. For example, previous work on Adélies at Ross Island found a significant effect of 'memory' on where penguins foraged from one trip to the next, as long as only a few days elapsed between trips, apparently diluting the somewhat weak signal attributable to physical features that might predict where a penguin would forage (Ford et al. 2015).

Although there is a high correlation between surface chlorophyll and depth-integrated chlorophyll in the Ross Sea (e.g. Arrigo et al. 2000), the surface conditions detected by remote sensing may not be sufficient to describe the conditions at a depth relevant to prey aggregations and penguin foraging. The recent development and use of autonomous underwater vehicles to measure conditions below the surface (e.g. Oliver et al. 2013, Ainley et al. 2015, Cimino et al. 2016) holds great promise to expand our understanding of how surface conditions relate to conditions where prey aggregations occur. Ainley et al. (2015) used an acoustically equipped glider to study prey distribution in our study area in 2012. The glider was deployed in only 1 of the 4 years of the study, so we did not analyze that data here, but our results highlight the need to continue exploring and expanding alternate methods of collecting in situ data on ocean conditions throughout the water column.

Finally, we acknowledge that the number of undulations per dive may only represent a rough approximation of prey capture. For penguins encountering a swarm of tiny crystal krill, a high number of prey may be captured without registering as an undulation. In a recent study, Watanabe \& Takahashi (2013) found that head movements were highly correlated with individual krill captures, but our instruments were primarily detecting larger, whole body movements and are likely underestimating prey capture, particularly when the prey are crystal krill. Nonetheless, we have no reason to expect that the trends would not be representative, so we think it is reasonable to expect that more undulations tend to represent more prey captures. It is also possible that by excluding shallow dives we excluded some important foraging behavior (see Watanabe \& Takahashi 2013). However, glider data from 2012 (Ainley et al. 2015) indicates that krill and fish aggregations in the study area were mostly below $40 \mathrm{~m}$, suggesting that little foraging would have been excluded by our $10 \mathrm{~m}$ cutoff. Overall, our findings suggest that finer spatial and temporal scale data are necessary to accurately describe the environmental variables that correlate with penguin foraging success, and reinforce the promise of small, animalborne sensors for evaluating ecosystem processes.

Acknowledgements. The work of V.T., G.B., A.E.S., D.J., S.V. and D.G.A. was funded by NSF grants OPP 9526865, 9814882, 0440643 and 1543498, with very proficient logistical support provided by the US Antarctic Program. Handling of penguins was done under permit from the Antarctic Conservation Act, as well as the ethical use committee of San Jose State University. V.T. received additional support from the School of Earth Sciences, Stanford University. The participation of K.R.A. was supported by NSF grant OPP 1643618. For assistance with fieldwork we thank M. Hester, D. Hyrenbach, K. Lindquist, A. Lescroel, V. Marsaudon, V. Patil, and N. Strycker. G. van Dijken and N. Elliott assisted with remote sensing data processing. We also thank L. Salas for help with R scripts and programming and B. Nickel for helpful feedback regarding the spatial analyses. Our modeling analyses benefited greatly from consultation with T. Hastie. This is Point Blue Conservation Science contribution \#2174.

\section{LITERATURE CITED}

Ainley DG, Ballard G (2012) Non-consumptive factors affecting foraging patterns in Antarctic penguins: a review and synthesis. Polar Biol 35:1-13

Ainley DG, Emison WB (1972) Sexual size dimorphism in Adélie penguins. Ibis 114:267-271

Ainley DG, O'Connor EF, Boekelheide RJ (1984) The marine ecology of birds in the Ross Sea, Antarctica. Ornithol Monogr, Vol 32. American Ornithological Union, Washington, DC

Ainley DG, Wilson PR, Barton KJ, Ballard G, Nur N, Karl B (1998) Diet and foraging effort of Adélie penguins in relation to pack-ice conditions in the southern Ross Sea. Polar Biol 20:311-319

Ainley DG, Ballard G, Barton KJ, Karl BJ, Rau GH, Ribic CA, Wilson PR (2003) Spatial and temporal variation of diet within a presumed metapopulation of Adélie penguins. Condor 105:95-106

Ainley DG, Ribic CA, Ballard G, Heath S and others (2004) Geographic structure of Adélie penguin populations: overlap in colony-specific foraging areas. Ecol Monogr 74:159-178 
Ainley DG, Ballard G, Dugger KM (2006) Competition among penguins and cetaceans reveals trophic cascades in the western Ross Sea, Antarctica. Ecology 87: 2080-2093

Ainley DG, Dugger KD, Ford RG, Pierce SD and others (2009) The spatial association of predators and prey at frontal features in the northern California current: competition, facilitation, or merely co-occurrence. Mar Ecol Prog Ser 389:271-294

* Ainley DG, Ballard G, Blight LK, Ackley S and others (2010) Impacts of cetaceans on the structure of Southern Ocean food webs. Mar Mamm Sci 26:482-498

Ainley DG, Ribic CA, Woehler EJ (2012) Adding the ocean to the study of seabirds: a brief history of at-sea seabird research. Mar Ecol Prog Ser 451:231-243

Ainley DG, Ballard G, Jones RM, Jongsomjit D, Pierce SD, Smith WO Jr, Veloz S (2015) Trophic cascades in the western Ross Sea, Antarctica: revisited. Mar Ecol Prog Ser 534:1-16

Arrigo KR, van Dijken GL (2004) Annual changes in sea-ice, chlorophyll $a$, and primary production in the Ross Sea, Antarctica. Deep Sea Res II 51:117-138

Arrigo KR, Weiss AM, Smith WO Jr (1998) Physical forcing of phytoplankton dynamics in the southwestern Ross Sea. J Geophys Res Oceans 103:1007-1021

Arrigo KR, Robinson DH, Worthen DL, Dunbar RB, DiTullio GR, VanWoert M, Lizotte MP (1999) Phytoplankton community structure and the drawdown of nutrients and $\mathrm{CO}_{2}$ in the Southern Ocean. Science 283:365-367

Arrigo KR, DiTullio GR, Dunbar RB, Robinson DH, VanWoert M, Worthen DL, Lizotte MP (2000) Phytoplankton taxonomic variability in nutrient utilization and primary production in the Ross Sea. J Geophys Res 105: 8827-8846

* Arrigo KR, van Dijken GL, Ainley DG, Fahnestock M, Markus T (2002) Ecological impact of a large Antarctic iceberg. Geophys Res Lett 29:8-1-8-4

Arrigo KR, van Dijken GL, Bushinsky S (2008) Primary production in the Southern Ocean, 1997-2006. J Geophys Res 113:1-27

Arrigo KR, Mills MM, Kropuenske LR, van Dijken GL, Alderkamp AC, Robinson DH (2010) Photophysiology in two major Southern Ocean phytoplankton taxa: photosynthesis and growth of Phaeocystis antarctica and Fragilariopsis cylindrus under different irradiance levels. Integr Comp Biol 50:950-966

Arrigo KR, van Dijken GL, Strong AL (2015) Environmental controls of marine productivity hot spots around Antarctica. J Geophys Res Oceans 120:5545-5565

Ballance LT, Ainley DG, Hunt GL Jr (2001) Seabird foraging ecology. In: Stelle JH, Thorpe SA, Turekian KK (eds) Encyclopedia of ocean sciences. Academic Press, San Diego, CA, p 2636-2644

Ballance LT, Ainley DJ, Ballard G, Barton K (2009) An energetic correlate between colony size and foraging effort in seabirds, an example of the Adélie penguin Pygoscelis adeliae. J Avian Biol 40:279-288

Ballard G, Ainley DG, Ribic CA, Barton KR (2001) Effect of instrument attachment and other factors on foraging trip duration and nesting success of Adélie penguins. Condor 103:481-490

Ballard G, Toniolo V, Ainley DG, Parkinson CL, Arrigo KR, Trathan PN (2010a) Responding to climate change: Adélie penguins confront astronomical and ocean boundaries. Ecology 91:2056-2069
Ballard G, Dugger KM, Nur N, Ainley DG (2010b) Foraging strategies of Adélie penguins: adjusting body condition to cope with environmental variability. Mar Ecol Prog Ser 405:287-302

* Ballard G, Jongsomjit D, Veloz SD, Ainley DG (2012) Coexistence of mesopredators in an intact polar ocean ecosystem: the basis for defining a Ross Sea marine protected area. Biol Conserv 156:72-82

* Bannasch R, Wilson RP, Culik B (1994) Hydrodynamic aspects of design and attachment of a back-mounted device in penguins. J Exp Biol 194:83-96

* Beans C, Hecq JH, Koubbi P, Vallet C, Wright S, Goffart A (2008) A study of the diatom-dominated microplankton summer assemblages in coastal waters from Terre Adélie to the Mertz Glacier, East Antarctica $\left(139^{\circ} \mathrm{E}-145^{\circ} \mathrm{E}\right)$. Polar Biol 31:1101-1117

Bond DS, Henderson FP (1963) The conquest of darkness. Report AD 346297. Defense Documentation Center, Alexandria, VA

* Bost CA, Handrich Y, Butler PJ, Fahlman A, Halsey LG, Woakes AJ, Ropert-Coudert Y (2007) Changes in dive profiles as an indicator of feeding success in king and Adélie penguins. Deep Sea Res II 54:248-255

* Bost CA, Cotté C, Bailleul F, Cherel Y and others (2009) The importance of oceanographic fronts to marine birds and mammals of the southern oceans. J Mar Syst 78:363-376

* Buston PM, Elith J (2011) Determinants of reproductive success in dominant pairs of clownfish: a boosted regression tree analysis. J Anim Ecol 80:528-538

* Cavalieri DJ, Markus T, Comiso JC (2013) AMSR-E/Aqua daily L3 $12.5 \mathrm{~km}$ sea ice concentration grids, version 3 . NASA National Snow \& Ice Data Center, Distributed Active Archive Center, Boulder, CO. doi:10.5067/AMSRE/AE_SI12.003 (accessed 24 June 2013)

* Cimino MA, Moline MA, Fraser WR, Patterson-Fraser DL, Oliver MJ (2016) Climate-driven sympatry may not lead to foraging competition between congeneric top-predators. Sci Rep 6:18820

Davey FJ (2004) Ross Sea bathymetry, 1:2,000,000, version 1.0. Institute of Geological \& Nuclear Sciences geophysical map 16. Institute of Geological \& Nuclear Sciences Limited, Lower Hutt

*De'ath G, Fabricius KE (2000) Classification and regression trees: a powerful yet simple technique for ecological data analysis. Ecology 81:3178-3192

DeWitt HH (1970) The character of the midwater fish fauna of the Ross Sea, Antarctica. In: Holdgate MW (ed) Antarctic ecology. Academic Press, London, p 305-314

* Dugger KM, Ainley DG, Lyver PO'B, Barton K, Ballard G (2010) Survival differences and the effect of environmental instability on breeding dispersal in an Adélie penguin meta-population. Proc Natl Acad Sci USA 107: 12375-12380

* Dugger KM, Ballard G, Ainley DG, Lyver PO'B, Schine C (2014) Adélie penguins coping with environmental change: results from a natural experiment at the edge of their breeding range. Front Ecol Evol 2:1-12

*Eastman JT (1985) Pleuragramma antarcticum (Pisces, Nototheniidae) as food for other fishes in McMurdo Sound, Antarctica. Polar Biol 4:155-160

Eastman JT (1993) Antarctic fish biology: evolution in an unique environment. Academic Press, San Diego, CA

Elith J, Graham CH, Anderson RP, Dudík M and others (2006) Novel methods improve prediction of species' distributions from occurrence data. Ecography 29:129-151 
Elith J, Leathwick JR, Hastie T (2008) A working guide to boosted regression trees. J Anim Ecol 77:802-813

ESRI (2008) ArcMap, version 9.3. Environmental Systems Research Institute, Redlands, CA

Ford RG, Ainley DG, Lescroël A, Lyver PO'B, Toniolo V, Ballard G (2015) Testing assumptions of central place foraging theory: a study of Adélie penguins Pygoscelis adeliae in the Ross Sea. J Avian Biol 46:193-205

Freitas C (2010) Argosfilter: argos locations filter. http:// cran.r-project.org/web/packages/argosfilter/ (accessed 11 April 2017)

Freitas C, Lydersen C, Fedak MA, Kovacs KM (2008) A simple new algorithm to filter marine mammal Argos locations. Mar Mamm Sci 24:315-325

Friedman JH, Meulman JJ (2003) Multiple additive regression trees with application in epidemiology. Stat Med 22: 1365-1381

* Georges JY, Guinet C, Jouventin P, Weimerskirch H (1997) Satellite tracking of seabirds: interpretation of activity pattern from the frequency of satellite locations. Ibis 139: 403-405

* Gerringa LJA, Laan P, van Dijken GL, van Haren H, De Baar HJW, Arrigo KR, Alderkamp AC (2015) Sources of iron in the Ross Sea polynya in early summer. Mar Chem 177: 447-459

Haberman KL, Ross RM, Quetin LB, Vernet M, Nevitt GA, Kozlowski W (2002) Grazing by Antarctic krill Euphausia superba on Phaeocystis antarctica: an immunochemical approach. Mar Ecol Prog Ser 241:139-149

*Hamer KC, Phillips RA, Wanless S, Harris MP, Wood AG (2000) Foraging ranges, diets and feeding locations of gannets Morus bassanus in the North Sea: evidence from satellite telemetry. Mar Ecol Prog Ser 200:257-264

Hastie T, Tibshirani R, Friedman J (2009) The elements of statistical learning: data mining, inference, and prediction, 2nd edn. Springer-Verlag, New York

* Hunt GL Jr, McKinnel S (2006) Interplay between top-down, bottom-up, and wasp-waist control in marine ecosystems. Prog Oceanogr 68:115-124

*Hijmans RJ (2016) raster: geographic data analysis and modeling. $\mathrm{R}$ package version 2.6-7. https://CRAN.Rproject.org/package=raster

Hijmans RJ, Phillips S, Leathwick J, Elith J (2017) Package 'dismo'. R package documentation. https://cran.r-project. org/web/packages/dismo/dismo.pdf (accessed 21 July 2017)

Hopkins TL (1987) Midwater food web in McMurdo Sound, Ross Sea, Antarctica. Mar Biol 96:93-106

Jacobs SS, Comiso JC (1989) Sea ice and oceanic process on the Ross Sea continental shelf. J Geophys Res 94: 18195-18211

Jacobs SS, Giulivi CF, Mele PA (2002) Freshening of the Ross Sea during the Late 20th century. Science 297: 386-389

JAXA (Japanese Aerospace Exploration Agency) (2013) AMSR-2 daily L2 $6.25 \mathrm{~km}$ sea ice concentration grids, version 1.1. Japanese Aerospace Exploration Agency, Global Change Observation Mission Portal, Tokyo. https:// gportal.jaxa.jp/gpr/?lang=en (accessed February 2013)

Kahl LA, Schofield O, Fraser WR (2010) Autonomous gliders reveal features of the water column associated with foraging by Adélie penguins. Integr Comp Biol 50:1041-1050

Karnovsky N, Ainley DG, Lee P (2007) The impact and importance of production in polynyas to top-trophic predators: three case histories. In: Smith WO, Barber
DG (eds) Polynyas: windows to the world. Elsevier, Amsterdam, p 391-410

Kooyman GL (1989) Diverse divers. Springer-Verlag, Berlin \& Heidelberg

Kropuenske LR, Mills MM, van Dijken GL, Bailey S, Robinson DH, Welschmeyer NA (2009) Photophysiology in two major Southern Ocean phytoplankton taxa: photoprotection in Phaeocystis antarctica and Fragilariopsis cylindrus. Limnol Oceanogr 54:1176-1196

*La Mesa M, Eastman JT (2012) Antarctic silverfish: life strategies of a key species in the high-Antarctic ecosystem. Fish Fish 13:241-266

*La Mesa M, Eastman JT, Vacchi M (2004) The role of notothenioid fish in the food web of the Ross Sea shelf waters: a review. Polar Biol 27:321-338

Kescroël A, Ballard G, Toniolo V, Barton KJ, Wilson PR, Lyver PO'B, Ainley DG (2010) Working less to gain more: when breeding quality relates to foraging efficiency. Ecology 91:2044-2055

* Lescroël A, Ballard G, Grémillet D, Authier M, Ainley DG (2014) Antarctic climate change: extreme events disrupt plastic response in Adélie penguins. PLOS ONE 9: e85291

* Lynch HJ, LaRue ML (2014) First global census of the Adélie penguin. Auk 131:457-466

* Lyver PO'B, Barron M, Barton KJ, Ainley DG and others (2014) Trends in the breeding population of Adélie penguins in the Ross Sea, 1981-2012: a coincidence of climate and resource extraction effects. PLOS ONE 9: e91188

Mills MM, Kropuenske LR, van Dijken GL, Alderkamp AC and others (2010) Photophysiology in two southern ocean phytoplankton taxa: photosynthesis of Phaeocystis antarctica (Prymnesiophyceae) and Fragilariopsis cylindrus (Bacillariophyceae) under simulated mixed-layer irradiance. J Phycol 46:1114-1127

NASA Goddard Space Flight Center (2013) Ocean Ecology Laboratory, Ocean Biology Processing Group. Moderateresolution Imaging Spectroradiometer (MODIS) Aqua Chlorophyll Data; 2018 Reprocessing. NASA OB.DAAC, Greenbelt, MD, doi:10.5067/AQUA/MODIS/L3B/CHL

Nevitt GA, Losekoot M, Weimerskirch H (2008) Evidence for olfactory search in wandering albatross, Diomedea exulans. Proc Natl Acad Sci USA 105:4576-4581

* Oliver MJ, Irwin A, Moline MA, Fraser W, Patterson E, Schofield O, Kohut J (2013) Adélie Penguin foraging location predicted by tidal regime switching. PLOS ONE 8:e55163

Orians GH, Pearson NE (1979) On the theory of central place foraging. In: Horn DJ, Mitchell RD, Stairs GR (eds) Analysis of ecological systems. Ohio State University Press, Columbus, OH, p 154-177

*Pakhomov EA, Perissinotto R (1996) Antarctic neritic krill Euphausia crystallorophias: spatio-temporal distribution, growth and grazing rates. Deep Sea Res I 43:59-87

Pakhomov EA, Perissinotto R (1997) Spawning success and grazing impact of Euphausia crystallorophias in the Antarctic shelf region. In: Battaglia B, Valencia J, Walton DWH (eds) Antarctic communities: species, structure, and survival. Cambridge University Press, Cambridge, p 187-192

*Parkinson CL (2002) Trends in the length of the Southern Ocean sea-ice season, 1979-99. Ann Glaciol 34:435-440

* Pelletier L, Kato A, Chiaradia A, Ropert-Coudert Y (2012) Can thermoclines be a cue to prey distribution for marine 
top predators? A case study with little penguins. PLOS ONE 7:e31768.

Pinkerton $\mathrm{MH}$, Forman J, Bury SJ, Brown J, Horn P, O'Driscoll RL (2013) Diet and trophic niche of Antarctic silverfish Pleuragramma antarcticum in the Ross Sea, Antarctica. J Fish Biol 82:141-164

R Development Core Team (2017) R: a language and environment for statistical computing, version 3.3.3. R Foundation for Statistical Computing, Vienna. www.Rproject.org/

Ribic CA, Ainley DG, Ford RG, Fraser WR, Tynan CT, Woehler EJ (2011) Water masses, ocean fronts, and the structure of Antarctic seabird communities: putting the eastern Bellingshausen Sea in perspective. Deep Sea Res II 58:1695-1709

Ropert-Coudert Y, Kato A, Baudat J, Bost CA, Le Maho Y, Naito Y (2001) Feeding strategies of free-ranging Adélie penguins Pygoscelis adeliae analysed by multiple data recording. Polar Biol 24:460-466

Ropert-Coudert Y, Kato A, Chiaradia A (2009) Impact of small-scale environmental perturbations on local marine food resources: a case study of a predator, the little penguin. Proc R Soc B 276:4105-4109

Russell RW, Harrison NM, Hunt GL Jr (1999) Foraging at a front: hydrography, zooplankton, and avian planktivory in the northern Bering Sea. Mar Ecol Prog Ser 182:77-93

Schapire RE (2003) The boosting approach to machine learning: an overview. In: Denison DD, Hansen $\mathrm{MH}$, Holmes CC, Mallick B, Yu B (eds) Nonlinear estimation and classification. Lect Notes Stat, Vol 171. Springer, New York, NY

Shealer DA (2002) Foraging behavior and food of seabirds. In: Schrieber EA, Burger J (eds) Biology of marine birds. CRC Press, Boca Raton, FL, p 137-178

Silverman ED, Veit RR, Nevitt GA (2004) Nearest neighbors as foraging cues: information transfer in a patchy environment. Mar Ecol Prog Ser 277:25-36

Simeone A, Wilson RP (2003) In-depth studies of Magellanic penguin (Spheniscus magellanicus) foraging: can we estimate prey consumption by perturbations in the dive profile? Mar Biol 143:825-831

Smith WO Jr, Nelson DM (1986) Importance of ice edge phytoplankton production in the Southern Ocean. Bioscience 36:251-257

Smith WO Jr, Ainley DG, Cattaneo-Vietti R (2007) Trophic interactions within the Ross Sea continental shelf ecosystem. Philos Trans R Soc Lond B Biol Sci 362:95-111

Editorial responsibility: Kyle Elliott,

Sainte-Anne-de-Bellevue, Québec
Smith WO Jr, Ainley DG, Arrigo KR, Dinniman MS (2014) The oceanography and ecology of the Ross Sea. Annu Rev Mar Sci 6:469-487

Stammerjohn S, Massom R, Rind D, Martinson D (2012) Regions of rapid sea ice change: an interhemispheric seasonal comparison. Geophys Res Lett 39:L06501

* Tagliabue A, Arrigo KR (2003) Anomalously low zooplankton abundance in the Ross Sea: an alternative explanation. Limnol Oceanogr 48:686-699

Takahashi A, Dunn MJ, Trathan PN, Croxall JP, Wilson RP, Sato K, Naito Y (2004) Krill-feeding behaviour in a chinstrap penguin Pygoscelis antarctica compared with fisheating in Magellanic penguins Spheniscus magellanicus: a pilot study. Mar Ornithol 32:47-54

Taki K, Yabuki T, Noiri Y, Hayashi T, Naganobu M (2008) Horizontal and vertical distribution and demography of euphausiids in the Ross Sea and its adjacent waters in 2004/2005. Polar Biol 31:1343-1356

* Tremblay Y, Shaffer SA, Fowler SL, Kuhn CE and others (2006) Interpolation of animal tracking data in a fluid environment. J Exp Biol 209:128-140

Veit RR (1999) Behavioural responses by foraging petrels to swarms of Antarctic krill Euphausia superba. Ardea 87: $41-50$

Warmerdam F (2013) FWTools: open source GIS binary kit for Windows and Linux. http://fwtools.maptools.org/ (accessed 24 June 2013)

*Watanabe YY, Takahashi A (2013) Linking animal-borne video to accelerometers reveals prey capture variability. Proc Natl Acad Sci USA 110:2199-2204

WWatanabe YY, Ito M, Takahashi A (2014) Testing optimal foraging theory in a penguin-krill system. Proc R Soc B 281:20132376

Wilson RP, Wilson MP (1989) Tape: a package-attachment technique for penguins. Wildl Soc Bull 17:77-79

*Wilson RP, Puetz K, Bost CA, Culik BM, Bannasch R, Reins $\mathrm{T}$, Adelung D (1993) Diel dive depth in penguins in relation to diel vertical migration of prey: whose dinner by candlelight? Mar Ecol Prog Ser 94:101-104

*Yen PPW, Sydeman WJ, Hyrenbach KD (2004) Marine bird and cetacean associations with bathymetric habitats and shallow-water topographies: implications for trophic transfer and conservation. J Mar Syst 50:79-99

*Yen PPW, Sydeman WJ, Morgan KH, Whitney FA (2005) Top predator distribution and abundance across the eastern Gulf of Alaska: temporal variability and ocean habitat associations. Deep Sea Res II 52:799-822

Submitted: April 9, 2018; Accepted: October 26, 2018

Proofs received from author(s): November 21, 2018 